\title{
GÊNERO TEXTUAL - FERRAMENTA NA LINGUAGEM PARA PRÁTICA DO ENSINO APRENDIZAGEM
}

\author{
José Michelson Benício Belo ${ }^{1}$ \\ Diógenes José Gusmão Coutinho ${ }^{2}$
}

RESUMO: Este artigo situa-se na discussão sobre o gênero textual como ferramenta do ensino aprendizagem e tem como objetivo principal observar, com base em discussões recentes sobre letramento de alunos no ambiente escolar realizada por Novos Estudos do Letramento. Demonstrando os impactos trazidos aos estudantes de ensino fundamental o gênero textual, mais especificamente, como uma ferramenta do ensino aprendizagem.

Palavras-Chave: Ensino aprendizagem. Gênero textual. Ensino fundamental

ABSTRACT: This paper is located in the discussion about the textual genre as a teaching learning tool and has as main objective to observe, based on recent discussions about students' literacy in the school environment held by New Literacy Studies. Demonstrating the impacts brought to elementary school students the textual genre, more specifically, as a tool of teaching learning.

Keywords: Teaching Learning. Textual genre. Elementary school.

\section{INTRODUÇÃO}

Tendo em vista a inserção de estudantes no ensino fundamental, é inquestionável a exigência com diversas habilidades de letramento no ambiente escolar, implicando assim uma maior capacidade de lidar com essas novas práticas de leitura e escrita. Partindo desse pressuposto, tendo os gêneros textuais como ferramenta do ensino aprendizagem, uma vez que, a partir desse gênero podem-se aplicar questões avaliativas de disciplinas e experiências no ensino, percebe-se a 3amplitude que o mesmo se constitui. Consoante a este posicionamento, Bhatia (2002, p. 66) defende que os gêneros textuais “[...] podem ser vistos por duas perspectivas diferentes. Na primeira, como reflexo do mundo e das práticas comunicativas nele presentes. Na segunda, como uma eficiente ferramenta pedagógica para

\footnotetext{
I Graduado em Letras pela FAFICA. Pós-Graduação Latu Sensu em Avaliação Educacional língua Portuguesa pela UFPE. Cursando Mestrado em Ciências da Educação pela Universidade Christian Business School E-mail: michelsonpe@gmail.com

2Doutor em Biologia pela UFPE. E-mail: alphadiogenes@gmail.com.
} 
o ensino aprendizagem". ${ }^{1}$ Ademais, nota-se a relevância de que se reveste esse gênero e sua função de contribuição no âmbito do ensino fundamental, e que por sua vez pode ser apresentado como um trabalho árduo pela falta de conhecimento por parte dos estudantes no que se refere aos gêneros textuais.

Outro fator que pode acarretar é a má distribuição de estratégias retóricas em determinadas áreas deste gênero. Diante de toda essa problemática, variados estudos contribuem significativamente sobre as convenções que permeiam esses mecanismos retóricos na área dos gêneros, como Hyland (2004), Parodi (2010) e Bhatia (2004), entre outros.

Considerando o gênero textual como ferramenta do ensino, saber lidar com aspectos que envolvem essa parte do ensino aprendizagem é colocar o gênero textual como um divisor de águas, pois nessa seção tem-se o reconhecimento de uma ferramenta relevante ou não, acarretando, muitas vezes, a diminuição de aprendizado pelos alunos de ensino fundamental. Sendo assim, para desenvolver sua teoria dos gêneros, Bakhtin faz críticas a algumas teorias linguísticas, especialmente nas discussões sobre a constituição do discurso, uma vez que, para muitas dessas teorias, falante e ouvinte assumem papéis estanques, em que o ouvinte exerce o papel apenas de receptor. Dessa forma, a aplicação deste modelo representa um auxílio no desenvolvimento das práticas de letramento da aprendizagem para alunos do ensino fundamental.

Sendo Bhatia, o pioneiro em se dedicar a análise da organização retórica de ensino aprendizagem, alguns pesquisadores se estenderam nesse viés e adaptaram esse recurso para outros gêneros, como o trabalho de Ritti-Dias e Bezerra (2013), que analisaram introduções em artigos na área de saúde pública. Igualmente, a Biasi-Rodrigues (1998) e Oliveira (2017) que se debruçaram no estudo do gênero resumo. Porém, faltam trabalhos que venham analisar comparativamente o ensino aprendizagem como ferramenta no que se refere à quais informações são incluídas em um e na outra parte, se existe coerência nessa distribuição de informações e se ambos são adequadamente informativos em conformidade com as expectativas da área disciplinar.

Ademais, o objetivo desta pesquisa é especificamente analisar o gênero textual como ferramenta na linguagem para prática do ensino aprendizagem, buscando colaborar com 
pesquisadores da área de gêneros textuais e contribuir para escritores desse gênero com o aprimoramento da escrita.

\section{METODOLOGIA}

A execução desta pesquisa manifestar-se-á segundo o que Marconi e Lakatos (2021, p. 242 ${ }^{4}$ denominam documentação indireta, o que diz respeito à pesquisa documental e bibliográfica. Outrossim, apoiando-se nas lições de Bauer e Gaskell (2002, p. 39)5 para quem "toda pesquisa social empírica seleciona evidência para argumentar e necessita justificar a seleção da base de investigação, descrição, demonstração, prova ou refutação de uma afirmação específica" a presente pesquisa procura construir a sua base de investigação do gênero textual como ferramenta na linguagem para prática do ensino aprendizagem.

Inicialmente serão analisadas bibliografias com maior precisão o que é gênero textual e o ensino aprendizagem, tendo em vista a possibilidade de ferramenta linguística.

Após, serão relacionados o gênero textual como ferramenta na linguagem para prática do ensino aprendizagem. Por fim, analisar-se-á quais impactos trazidos pelo uso do gênero textual como ferramenta no ensino aprendizagem nas escolas.

\section{FUNDAMENTAÇÃO TEÓRICA}

\section{I LETRAMENTO NAS SÉRIES INICIAIS DO ENSINO FUNDAMENTAL}

O ingresso no ensino fundamental envolve o desenvolvimento de novos requisitos de habilidades no processo de leitura e escrita. Portanto, cabe destacar que o estudo da performance de leitura e escrita se deve, principalmente, ao conceito de tempo e espaço e suas respectivas formas no processo de leitura e escrita

Para estimular a perspectiva do letramento, Brian Street $(1984)^{6}$ elabora dois conceitos reflexivos pertinentes às práticas de leitura e escrita. Sendo estes conhecidos por padrão independente e o padrão ideológico; o primeiro modelo apresenta-se conforme uma

\footnotetext{
4 Eva Maria Lakatos; Marina de Andrade Marconi, p.242, METODOLOGIA DO TRABALHO CIENTÍFICO - 9-aE. (2021

5 Martin W. Bauer e George Gaskell. Petrópolis: Editora Vozes, 2002, p.39

${ }^{6}$ Literacy in Theory and Practice
} 
capacidade universal, técnica e neutra. Nesse entendimento a produção da compreensão e a escrita é vista de forma simplificada e contextualizada, sendo ela mesma responsável por garantir que todos os fatores envolvidos na esfera social estejam envolvidos. No entanto, o segundo modelo se opõe a essa definição e usa a alfabetização como um conjunto de práticas sociais, reivindicando a diversidade de contextos, e diferentes trabalhos de leitura e escrita que expõem ideologias. Portanto, ao se perceber que o processo de alfabetização envolve valores ideológicos, as pesquisas relacionadas ao letramento acadêmico permeiam os preconceitos que cercam a prática social da leitura e da produção da escrita em um ambiente acadêmico.

Partindo dessa proposição, o letramento acadêmico torna-se um instrumento de uso social que corrobora junto à prática de leitura e escrita no ensino fundamental devido às diversas habilidades de escrita que se constitui o assunto escolar. Para isso, torna-se essencial alertar discentes que estão ingressando nas escolas de ensino fundamental sobre a reivindicação de produção textual existente e oferecer meios para os que já estão dentro participando dessas esferas escolares.

\subsection{MODELO DE ENSINO APRENDIZAGEM E SUA ADAPTAÇÃO PROPOSTA POR BIASI-RODRIGUES E BAKHTIN}

A proposta sociocorretórica do teórico John M. Swales baseia-se em análises de gêneros textuais relacionadas a contextos de ensino aprendizagem. Sendo assim, suas pesquisas contribuem no ensino de gêneros através das práticas sociais, corroborando a capacidade dos indivíduos na produção de um determinado texto com as características que envolvem o gênero textual em evidência. Em consonância com tal aspecto, nota-se que as práticas sociais propostas na apresentação de Swales reverberam na escolha de componentes linguísticos. De acordo com Hemais e Biasi-Rodrigues,

[...] Swales se mantém a uma abordagem que se apoia em uma análise linguística que revela muito da construção do texto e das práticas sociais que determinam as escolhas linguísticas que configuram o texto. Pode-se dizer que determinam as escolhas linguísticas que configuram o texto. Pode-se dizer que para Swales, essa abordagem, tem grande relevância para 
o ensino, visto que a conscientização linguística torna o ensino/aprendizagem mais eficaz (2005, p. 109)7.

Portanto, percebe-se que a máxima fundamentada por Swales, através das autoras, reverbera na utilização de determinadas escolhas na produção textual. Sendo assim, toda escolha linguística parte de uma ação social e cultural que acarreta as diversas práticas de escrita. Dessa forma, é evidente que toda análise textual deve ser averiguada por meio de um contexto em que a escrita foi organizada e não apenas um olhar para as escolhas linguísticas. Desse modo, tal realização das escolhas linguísticas está relacionada aos reflexos da situação comunicacional em que é inserido o indivíduo.

Ainda no que tange à proposta de Swales, no que diz respeito aos gêneros estabelecidos na sociedade, eles permitem uma percepção e um entendimento para atingir uma finalidade, ou seja, para todo processo de execução de um gênero textual, a aplicação torna-se o elemento crucial, pois a partir de seu entendimento e a sua utilidade a compreensão do gênero torna-se eficiente. Para formular uma compreensão nítida no que diz respeito aos gêneros, Swales (1990) define que o gênero relaciona-se com a ideia de classe dessa forma, o gênero é visto como uma classe de eventos comunicacionais, e partir disso, os eventos permeiam situações em que a linguagem verbal é ampliada e assim, desfrutam o entendimento do que está sendo produzido e repassado através de um propósito comunicacional. Contudo, devem-se considerar as características que assumem determinado gênero textual.

A partir dessa questão, é importante ressaltar que com o avanço dos estudos linguísticos e com a entrada do texto e do discurso também como objetos de estudo da Linguística, os gêneros textuais passaram a fazer parte das reflexões de muitos estudiosos. Objetivando discutir teoricamente essa questão, expomos, a seguir, as principais teorias relacionadas a alguns teóricos e estudiosos da área, enfocando os aspectos que serão abordados na análise dos dados da pesquisa.

\footnotetext{
7 HEMAIS, Barbara. BIASI-RODRIGUES, Bernadete. A proposta sócio-retórica de John M. Swales para o estudo de gêneros textuais. In: MEURER, J. L.; BONINI, A.; MOTTA-ROTH, D. (Org.). Gêneros: teorias, métodos, debates. São Paulo: Parábola, 2005.
} 
Os estudos do russo Mikhail Bakhtin (2003) se destacam nas questões relativas aos gêneros do texto, em decorrência da sua preocupação com o discurso como um todo e com as condições de produção e recepção da atividade verbal.

Mesmo que o direcionamento das discussões acerca dos gêneros discursivos de Bakhtin não tenha enfocado a área de ensino e aprendizagem de línguas, suas ideias têm influenciado as pesquisas de muitos autores, tomando como base, na maioria das vezes, suas concepções concernentes aos gêneros (ANTUNES, 2002; BIASI-RODRIGUES, 2002; MARCUSCHI, 2003a; MARCUSCHI, 2003b; ANTUNES, 2003; SOUZA, 2003; ANTUNES, 2005; RODRIGUES, 2005).

Bakhtin (2003) afirma que o uso da língua se concretiza por meio de enunciados. Tais enunciados são individuais e únicos. Apesar disso, "cada campo de utilização da língua elabora seus tipos relativamente estáveis de enunciados" (orais ou escritos) e esses são de possibilidades inesgotáveis dentro dos diversos campos da atividade humana. Isso porque a diversidade dos gêneros segue os parâmetros sociais e históricos das práticas discursivas de um determinado universo social (BAKHTIN, 2003, p. 262) ${ }^{8}$.

Para Bakhtin, os gêneros têm seu próprio âmbito de existência e não podem ser substituídos aleatoriamente. O que determina o uso deste ou daquele gênero são as necessidades comunicativas dos membros de uma determinada esfera da atividade social. Para ele, "os enunciados e seus tipos, isto é, os gêneros discursivos, são correias de transmissão entre a história da sociedade e a história da linguagem" (BAKHTIN, 2003, p. 268)9. É mediante as necessidades do seu uso que os fenômenos linguísticos surgem no sistema da língua. "Nenhum fenômeno novo (fonético, léxico, gramatical) pode integrar o sistema da língua sem ter percorrido um complexo e longo caminho de experimentação e elaboração de gêneros e estilos" (BAKHTIN, 2003, p. 268). ${ }^{\text {o }}$

Bakhtin apresenta como base para os seus estudos sócio interacionais, principalmente, o caráter dialógico da linguagem, que também funcionou como marco para os estudos dos gêneros discursivos. Para desenvolver sua teoria dos gêneros, Bakhtin faz críticas a algumas teorias linguísticas, especialmente nas discussões sobre a constituição do

\footnotetext{
${ }^{8}$ Bakthin, M. (2003). Estética da criação verbal. São Paulo: Martins Fontes.

9 Ibidem

ro Ibidem
} 
discurso, uma vez que, para muitas dessas teorias, falante e ouvinte assumem papéis estanques, em que o ouvinte exerce o papel apenas de receptor. Esse tipo de concepção é tido, por Bakhtin, até certo ponto, como ficção. Para ele,

O ouvinte, ao perceber e compreender o significado (linguístico) do discurso, ocupa simultaneamente em relação a ele uma ativa posição responsiva: concorda ou discorda dele (total ou parcialmente), completa-o, aplica-o, prepara-se para usá-lo, etc. (...) toda compreensão é prenhe de resposta, e nessa ou naquela forma a gera obrigatoriamente: o ouvinte se torna falante". (BAKHTIN, 2003, p. 27I).

O enunciado não acaba na compreensão do significado. O outro, o interlocutor, está sempre na produção do discurso, na constituição dos sentidos, mesmo que o seu turno de voz não se manifeste de imediato, ou, ainda, mesmo que ele não se manifeste verbalmente. O enunciado é sempre ativamente respondido. Essa interação se dá em forma de cooperação mútua, de acordos, de desacordos entre os interlocutores, que, completam os discursos ou se preparam para deles fazer uso. (BAKHTIN, 2003).

É nessa perspectiva que nossa pesquisa se direciona para o livro didático. De acordo com essa teoria, os textos produzidos pelos alunos na escola não são unilaterais; não acabam depois de sua produção. Eles são dirigidos a alguém (seja ao destinatário real ou não), e isso deve ser considerado pelo professor e pelos autores dos materiais didáticos utilizados nas aulas de línguas. Esses textos devem dar lugar à palavra do outro, à resposta do outro, tornando-se, assim, um elo na interação social, no contexto da sala de aula. É, então, função da escola também buscar o estabelecimento desse elo, para que esses textos possam ter significados reais para os alunos.

Desse modo, Bakhtin argumenta que as palavras e as orações, ao serem tratadas fora de um contexto, tornam-se impessoais; não são ditas nem escritas para ninguém. Mas, em se tratando de enunciados concretos, inseridos em uma prática social, existe um autor e um destinatário.

Nesse contexto, convém ressaltar que os trabalhos de Marcuschi (2003a, 2003b, 2006) ${ }^{\mathrm{II}}$ apresentam uma discussão acerca dos gêneros textuais e suas especificidades. $\mathrm{O}$ autor ta mbém chama a atenção para a distinção entre gênero textual e tipo textual, tão comumente

11 MARCUSCHI, Luiz Antônio. Gêneros textuais: definição e funcionalidade. In: DIONISIO, A. P.; MACHADO, A. R. e BEZERRA, M. A. (orgs.). Gêneros textuais \& ensino. 2. ed. Rio de Janeiro: Lucerna, 2003a, p. 19-36 
confundidos na escola. Marcuschi levanta vários argumentos como forma de distinguir essas duas entidades e apresenta uma noção de gênero textual inserida em um contexto sócio-histórico.

Devido ao fato de o termo gênero estar, tradicionalmente, atrelado aos estudos literários, é comum, na escola, o uso do termo tipo de texto para gênero de texto, relacionando-o assim a carta, memorando, reportagem, artigo de opinião etc. Isso constitui um equívoco na construção do conhecimento na sala de aula de línguas, pois muitas das propostas de produção de texto, oral ou escrito, se referem aos tipos textuais e não aos gêneros. Marcuschi esclarece essa questão argumentando que tipo de texto são sequências textuais definidas pela natureza linguística de sua composição, como aquelas propostas por Adam (I99I). ${ }^{12} \mathrm{O}$ que chamamos de gêneros textuais está muito além dessas sequências, envolvem características específicas como propósito comunicativo, interlocutores, suporte etc.

Para Marcuschi, os gêneros caracterizam-se muito mais por suas funções comunicativas, cognitivas e institucionais do que por suas peculiaridades linguísticas e estruturais; mas isso não quer dizer que a forma deve ser desprezada. De acordo com o autor, os gêneros textuais são "fenômenos históricos, profundamente vinculados à vida cultural e social" (MARCUSCHI, 2003a, p. 19) ${ }^{13}$ e colaboram para a ordenação e estabilização das atividades comunicativas do dia a dia. Talvez seja por essa razão que, assim como surgem, podem desaparecer, pois seu funcionamento está vinculado às necessidades e atividades socioculturais e às inovações tecnológicas. A exemplo disso, temos a grande circulação do gênero e-mail e, paralelamente, uma enorme redução no uso do tradicional gênero carta pessoal

\subsection{GÊNEROS TEXTUAIS}

Os gêneros existem em todos os aspectos da sociedade. Eles organizam a linguagem e promovem propósitos de comunicação construídos em diferentes contextos. Bazerman

\footnotetext{
${ }^{12}$ ADAM, J-M. Cadre théorique d'une typologie séquentielle. Études de Linguistique Appliquée: textes, discours types et genres, n. 83, p. 6-I8, 1991.

${ }^{13}$ M MARCUSCHI, Luiz Antônio. Gêneros textuais: definição e funcionalidade. In: DIONISIO, A. P.; MACHADO, A. R. e BEZERRA, M. A. (orgs.). Gêneros textuais \& ensino. 2. ed. Rio de Janeiro: Lucerna, 2003a, p. 19-36
} 
(2009 $)^{14}$ destacou que compreender os gêneros e suas funções em sistemas e ambientes pode ajudar os escritores a atender às necessidades da situação e possibilitar que esses gêneros sejam compreensíveis e respondam às expectativas dos outros. Desta forma, o gênero tem a função que o autor deseja transmitir e é amparado pela objetividade e função social que desempenha, quando essa forma não é conhecida por terceiros, o propósito é obviamente inválido. Compreender todos os aspectos do gênero penetrante não é apenas pesquisar o equivalente a expressões estruturadas, mas também descobrir comportamentos sociais realizados pela linguagem que torna a persistência dos indivíduos no mundo clara e eficaz. Motta Roth (2013, p.132) afirma que "de tal sorte que a linguagem é parte integral de uma atividade, a ponto de os gêneros tornarem-se fenômenos estruturadores da cultura". ${ }^{\text {s }}$ Bhatia (2004) discorre que a linguagem em determinadas esferas são textos, gêneros, prática profissional, prática social no mundo real, consequentemente, ela se torna partícula de inserção para propósitos comunicativos em contextos específicos.

Tendo o contexto de ensino como uma área vasta de realizações referente aos propósitos comunicativos, conhecer e dominar aspectos linguísticos torna-se um trabalho cauteloso e muitas vezes, desempenha nos discentes um grau de complexidade.

Sendo assim, a escrita no ensino fundamental envolve habilidades necessárias no que se refere a sua produção, que estão relacionados aos reflexos tanto na configuração quanto gênero textual. Como já foi dito pelos autores acima é um texto usado como ferramenta e ao que esse material produz, pois seu objetivo é ser compartilhado como forma de conhecimentos socializados acerca da área examinada.

\section{GÊNEROS TEXTUAIS E ENSINO}

Nos últimos anos, mais especificamente, após o anúncio dos Parâmetros Curriculares Nacionais (PCN), as pesquisas sobre gêneros textuais começaram a ecoar no campo da linguística textual e sua relação com a língua de instrução. Esses estudos ajudam

\footnotetext{
${ }^{14}$ BAZERMAN, Charles. Gêneros textuais, tipificação/ Charles Bazerman, Ângela Paiva Dionísio, Judith Chamblis Hoffnagel (orgs.). Revisão técnica Ana Regina Vieira et al. São Paulo: Cortez Editora, 2005.

is MOTTA-ROTH, Désiriée. Análise crítica de gêneros com foco em notícia de popularização da ciência. In: SEIXAS, Lia PINHEIRO, Najara Ferrari (Org.) Gêneros: um diálogo entre comunicação e linguística. Florianópolis: Insular, 2013.
} 
a priorizar a interação real e o trabalho significativo com os textos escolares e a fazer sugestões de ensino por meio de uma abordagem baseada em gênero.

Inicialmente, é válido ressaltar que o direcionamento de Bakhtin para os usos reais da língua como forma de ensino. De acordo com o autor,

\begin{abstract}
A língua materna - sua composição vocabular e sua estrutura gramatical - não chega ao nosso conhecimento a partir de dicionários e gramáticas, mas de enunciações concretas que nós mesmos ouvimos e nós mesmos reproduzimos na comunicação discursiva viva com as pessoas que nos rodeiam. Nós assimilamos as formas da língua somente nas formas das enunciações e justamente com essas formas. As formas da língua e as formas típicas dos enunciados, isto é, os gêneros do discurso, chegam à nossa experiência e à nossa consciência em conjunto e estreitamente vinculadas. Aprender a falar significa aprender a construir enunciados (porque falamos por enunciados e não por orações isoladas e, evidentemente, não por palavras isoladas)" (BAKHTIN, 2003, p. 282-283) ${ }^{16}$
\end{abstract}

Portanto, é fundamental orientar as atividades educacionais com base nas seguintes premissas: Os alunos produzirão textos que incorporem discursos vívidos e interajam verbalmente entre si por meio de enunciados e não por meio de frases isoladas ou palavras individuais. Como afirma Bakhtin (2003, p. 265), "a língua passa a integrar a vida através de enunciados concretos (que a realizam); é igualmente através de enunciados concretos que a vida entra na língua".

Muitos autores sugerem o uso de métodos baseados em gênero, como Meurer (1997), Paltridge (2001), Antunes (2002), Biasi-Rodrigues (2002), Cristóvão (2002), etc. Segundo Cristóvão (2002) ${ }^{17}$, quando os trabalhos se baseiam no "modelo de ensino de gênero", alunos e professores podem realizar ações reflexivas, como analisar o contexto em que estão inseridos, descrever comportamentos docentes e informar as razões por trás deles. comportamentos, escolhas feitas, reconstruindo a prática em sala de aula.

Após o lançamento dos Parâmetros Curriculares Nacionais (PCN) em 1998, pelo menos algumas instituições de ensino e / ou alguns professores começaram a implementar uma abordagem baseada em gênero, embora as discussões sobre gêneros textuais tenham sido no campo da linguística, especialmente linguística textual. Embora não haja uma discussão mais aprofundada sobre os gêneros textuais, PCN (1998) reconheceu a necessidade de compreender as funções sociais e a organização dos textos falados e escritos,

\footnotetext{
${ }^{16}$ Ibidem

${ }^{17}$ CRISTOVÃO, 2002a;. FREITAS, 2003
} 
pois eles são utilizados em programas interativos de pessoas, marcados pelo mundo social ao seu redor.

Portanto, os gêneros textuais existem em todas as nossas práticas sociais porque só podemos nos comunicar verbalmente por meio deles, como visto em Bakhtin (2003):

A vontade discursiva do falante se realiza antes de tudo na escolha de um certo gênero de discurso. Essa escolha é determinada pela especificidade de um dado campo da comunicação discursiva, por considerações semânticoobjetais (temáticas), pela situação concreta da comunicação discursiva, pela composição pessoal dos seus participantes etc. (BAKHTIN, 2003, p. 282). ${ }^{18}$

Se acreditarmos que, como disse Bakhtin, a vontade de falar do falante se dá na escolha do gênero, então, no ensino dos gêneros textuais, o professor deve ter clareza sobre a finalidade comunicativa do gênero a ser utilizado e a vontade de falar do aluno. Isso é importante para que ele possa propor atividades, por exemplo, a partir da experiência do aluno em leitura e produção de textos em escolas ou possíveis mercados de trabalho, e as características composicionais do gênero textual e seus possíveis destinatários não sejam esquecidas na elaboração da proposta.

\section{CONSIDERAÇÕES FINAIS}

Em conclusão a estas observações sobre o tema em questão, pode-se dizer que a utilização de gêneros textuais é uma excelente oportunidade para lidar com os mais diversos usos reais da linguagem cotidiana. Porque tudo o que fazemos na linguagem não pode ser feito em nenhum tipo. Portanto, tudo o que fazemos na linguagem pode ser tratado de um tipo ou de outro. E são muitos os gêneros que são produzidos sistematicamente, que têm um grande impacto no dia a dia e merecem a nossa atenção. Incluir, talvez fundamentalmente falando, as mídias que aparecem nas várias mídias existentes hoje, não exclui as mídias virtuais com as quais os usuários ou navegadores da Internet estão familiarizados.

Por fim, vale reiterar que a cooperação com os gêneros será uma forma de explicar o ensino dentro de uma das transportadoras da proposta oficial de parâmetros curriculares nacionais que aderem a essa visão. Além disso, tem-se a oportunidade de observar tanto a oralidade como a escrita em seus usos culturais mais autênticos sem forçar a formação de gêneros que conduzem apenas no universo escolar. Os trabalhos incluídos nesta pesquisa

\footnotetext{
${ }^{18}$ Ibidem
} 
buscam oferecer recomendações bastante claras e concretas de observação dos gêneros textuais na perspectiva aqui sugerida e com algumas alterações teóricas que cada autor dos textos adota em função de seus interesses e de suas sugestões de trabalho. No conjunto, a diferença de observações deverá ser um benefício a mais para quem vier a usufruir dessas análises

\section{REFERÊNCIAS}

ADAM, J-M. Cadre théorique d'une typologie séquentielle. Études de Linguistique Appliquée: textes, discours types et genres, n. 83, p. 6-18, 1991.

ANTUNES, Maria Irandé Costa Morais. Língua, gêneros textuais e ensino: considerações teóricas e implicações pedagógicas. Perspectiva: Revista do Centro de Ciências da Educação. Universidade Federal de Santa Catarina. Centro de Ciências da Educação - v. 20, n I. Florianópolis, 2002. 65-75.

BAKHTIN, Mikhail. Marxismo e Filosofia da Linguagem. 8a ed. São Paulo: Hucitec, 1997 (VOLOCHINOV, V. N).

BAKTHIN, M. (2003). Estética da criação verbal. São Paulo: Martins Fontes.

BEZERRA, Benedito G. Letramentos acadêmicos na perspectiva dos gêneros textuais. Fórum Linguístico, Florianópolis, v. 9, n. 4, p. 247-258, 2012.

BIASI-RODRIGUES, B.; HEMAIS, B.; ARAÚJO, J. C. O gênero resumo: uma prática discursiva da comunidade. In: BIASI-RODRIGUES, B.; ARAÚJO, J. C.; SOUSA, S. C. T. (Orgs.). Gêneros textuais e comunidades discursivas: um diálogo com John Swales. Belo Horizonte: Autêntica, 2009. p. 49-75.

BIASI-RODRIGUES, B.; HEMAIS, B.; ARAÚJO, J. C. Análise de gêneros na abordagem de Swales: princípios teóricos e metodológicos. In: BIASI-RODRIGUES, B.; ARAÚJO, J. C.; SOUSA, S. C. T. (Orgs.). Gêneros textuais e comunidades discursivas: um diálogo com John Swales. Belo Horizonte: Autêntica, 2009. p. 17-32.

Gêneros textuais: definição e funcionalidade. In: DIONÍSIO, Ângela P. et al. Gêneros textuais e ensino. Rio de Janeiro: Lucerna, 2002c, p. 19-36.

MARCUSCHI, Luiz A. Gêneros textuais. Recife: 2002a. (apostila).

MOTTA-ROTH, D.; HENDGES, G. Produção textual na universidade. São Paulo: Parábola Editorial, 2oı. 
OLIVEIRA, Giovane Fernandes. Os estudos dos letramentos acadêmicos no Brasil: influências, origens e perspectivas. Revista DisSol, Pouso Alegre, v. 4, n. 5, p. 89-Ior,

RITTI-DIAS, Fernanda G.; BEZERRA, Benedito G. Análise retórica de introduções de artigos científicos da área da saúde pública. Horizontes de Linguística Aplicada, v. I2, n. I, p. 163-182, 2013

Texto, gêneros do discurso e ensino. In: ---. Estudos sobre o discurso. São Paulo: USP, 200ra, p. 257-285 (mimeo - manuscrito para livre docência)

Brian Street Literacy in Theory and Practice

Bakthin, M. (2003). Estética da criação verbal. São Paulo: Martins Fontes. 